\title{
Erratum to: Serum cytokine and glucose levels as predictors of poststroke fatigue in acute ischemic stroke patients
}

\author{
Heidi Ormstad • Hans Christian Dalsbotten Aass • \\ Karl-Friedrich Amthor • Niels Lund-Sørensen • \\ Leiv Sandvik
}

Published online: 26 November 2011

(C) Springer-Verlag 2011

Erratum to: J Neurol (2011) 258:670-676

DOI 10.1007/s00415-011-5962-8

Throughout the manuscript, the unit expressing the levels of cytokines was erroneously written as $\mu \mathrm{g} / \mathrm{ml}$ (micrograms per milliliter). The reported values were actually in $\mathrm{pg} / \mathrm{ml}$ (picograms per milliliter).

The online version of the original article can be found under doi:10.1007/s00415-011-5962-8.

H. Ormstad $(\bowtie)$

Vestre Viken Hospital Trust, Ringerike, Servicebox 13,

3530 Hønefoss, Norway

e-mail: heidi.ormstad@vestreviken.no

H. Ormstad

Department of Health Sciences, Buskerud University College,

Drammen, Norway

H. C. D. Aass

The R \& D Group, Department of Medical Biochemistry,

Oslo University Hospital, Ullevål, Oslo, Norway

K.-F. Amthor

Department of Neurology, Vestre Viken Hospital Trust,

Buskerud, Norway

N. Lund-Sørensen

Department of Radiology, Vestre Viken Hospital Trust,

Buskerud, Norway

L. Sandvik

Section of Biostatistics, Oslo University Hospital,

Ullevål, Oslo, Norway 